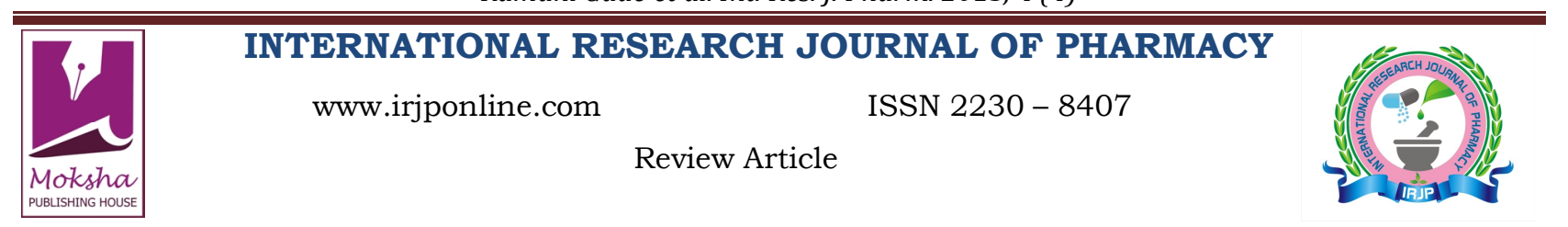

\title{
RecA: A NOVEL TARGET FOR DRUG DELIVERY
}

Ramani Gade*, Mohini Swetha L

Department of Pharmaceutics, Priyadarshini Institute of Pharmaceutical Education and Research, Pulladigunta, Guntur (DT), Andhrapradesh, India

Email: ramanigade169@gmail.com

Article Received on: 16/02/13 Revised on: 01/03/13 Approved for publication: 18/04/13

DOI: 10.7897/2230-8407.04413

IRJP is an official publication of Moksha Publishing House. Website: www.mokshaph.com

(C) All rights reserved.

\section{ABSTRACT}

The RecA protein is a recombinase functioning in recombinational DNA repair in bacteria. RecA is regulated at many levels. The expression of the recA gene is regulated within the SOS response. The activity of the RecA protein itself is autoregulated by its own C-terminus. RecA responsible for the development of resistance by the microbes against antibiotic. Development of new medication against RecA focus light on the future newer antibiotics in the phrma sector Keywords: RecA, Recombinational DNA, SOS response, C-terminus, antibiotics

\section{INTRODUCTION}

$\operatorname{RecA}$ (Recombination protein A) is a 38 kilodalton Escherichia coli protein essential for the repair and maintenance of DNA. A RecA structural and functional homolog has been found in every species in which one has been seriously sought and serves as an archetype for this class of homologous DNA repair proteins. The homologous protein in Homo sapiens is called RAD51. RecA has multiple activities, all related to DNA repair. In the bacterial SOS response, it has a co-protease function in the autocatalytic cleavage of the LexA repressor and the $\lambda$ repressor.

The RecA protein is a multifunctional protein that is essential to three distinct, but related biological processes:

- General genetic recombination.

- Regulation of the coordinated expression of many unlinked genes in response to DNA damage known as SOS response.

- The error-prone replicative bypass of DNA lesions, resulting in a highly mutagenic repair of DNA. Ot surprisingly, mutations in RecA are pleiotropic, affecting not only recombination, but also DNA repair mutagenesis and cell division. ${ }^{1,2}$

\section{Structure of RecA}

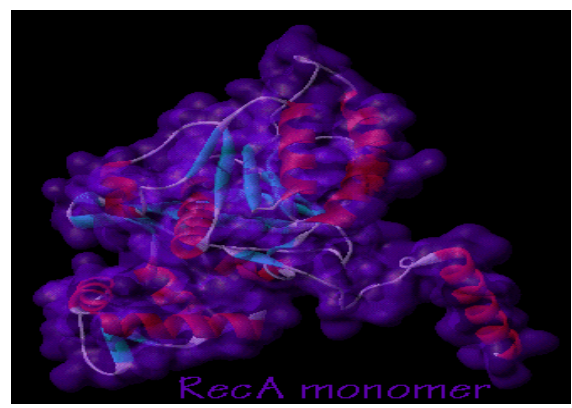

Figure : 1 RecA monomer

The RecA monomer consists of three domains, a large central domain, surrounded by relatively small amino and carboxy domains. The central domain, involved in DNA and ATP binding, consists primarily of a twisted beta sheet with 8 bstrands, bounded by 8 a-helices. The amino domain contains a large a-helix and short b-strand, this a/b structure being important in formation of the RecA polymer. Three a-helices and a three-stranded b-sheet are found in the carboxy domain, which facilitates interfilament associations. ${ }^{3}$

\section{Function of RecA}

For RecA protein to function in these processes, it must assemble on ssDNA to form a nucleoprotein filament known as the presynaptic complex. This filament is an adaptable structure, capable of performing three separate Functions:

- Homologous recombination (interaction with doublestranded DNA (dsDNA)),

- SOS induction (cleavage of the LexA repressor) and

- SOS mutagenesis (interaction with the processed Umu(D')2C complex).

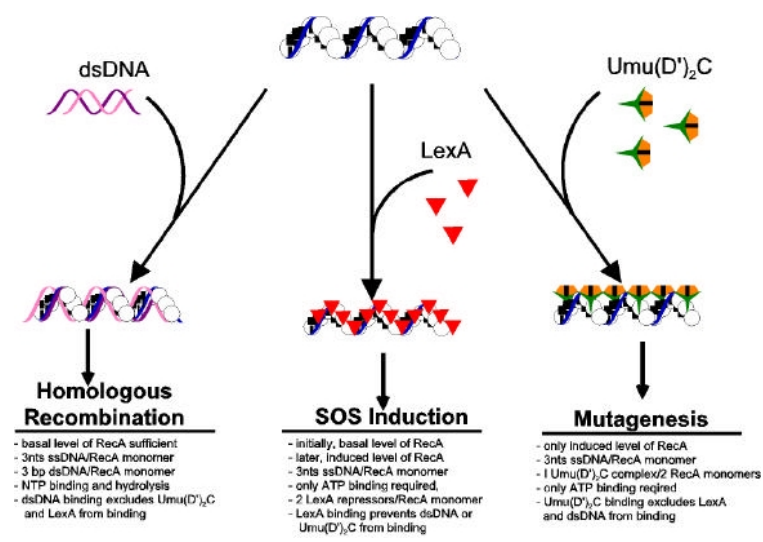

Figure :2 Role of the RecA nucleoprotein filament in DNA metabolism. A schematic showing the three mutually exclusive functions of the $\operatorname{Rec} A$ protein filament

The figure is adapted from rehrauer, W.M., Bruck, I., WOODGATE, R., Goodman, M. F., and kowalczykowski, S.C (1998)

The active nucleoprotein filament is a helical complex of RecA protein monomers wrapped around single-stranded DNA at a stoichiometry of 3 nucleotides/monomer and 6.2 monomers perturn (Figure 2A-D). Under certain conditions, RecA protein will also form filaments on dsDNA. Filament assembly is highly cooperative and occurs in the 5'3' direction relative to the ssDNA to which it is bound. The 
resulting filament has a regular, right-handed, helical structure, and the prominent feature is a large helical groove (Figure 2A). One side of the groove is smooth, while the other is penetrated by the protrusion of the individual monomers (Figure 2B). This groove is the binding site for the LexA repressor (22) and is proposed to be involved in the binding of dsDNA. The binding of the LexA repressor and dsDNA to the nucleoprotein filament is competitive, indicating that they bind at the same, or overlapping site, on the filament.

The nucleoprotein filament can exist in two forms: active and inactive. The inactive filament is formed in the absence of a nucleoside triphosphate cofactor and exists in a collapsed conformation with a helical pitch of 65 . The binding of a nucleoside triphosphate (NTP) cofactor (typically ATP), converts RecA protein to a high-affinity ssDNA-binding state, which is the active conformation of RecA protein that is required for all the activities of the protein. This active form of the filament has an extended conformation with a helical pitch of 95. It is this extended conformation that is the active species in RecA protein-promoted reactions. Within the active form of the nucleoprotein filament, the conformation of both ss- and dsDNA differs significantly from that of Bform DNA. The bound DNA is extensively stretched (to approximately $150 \%$ the length of B-form) and, in the case of dsDNA, the helix is also unwound. Electron micrographic analysis (Figure 2C) and neutron scattering reveal that the DNA is located near the axis of the nucleoprotein filament. ${ }^{4,5}$
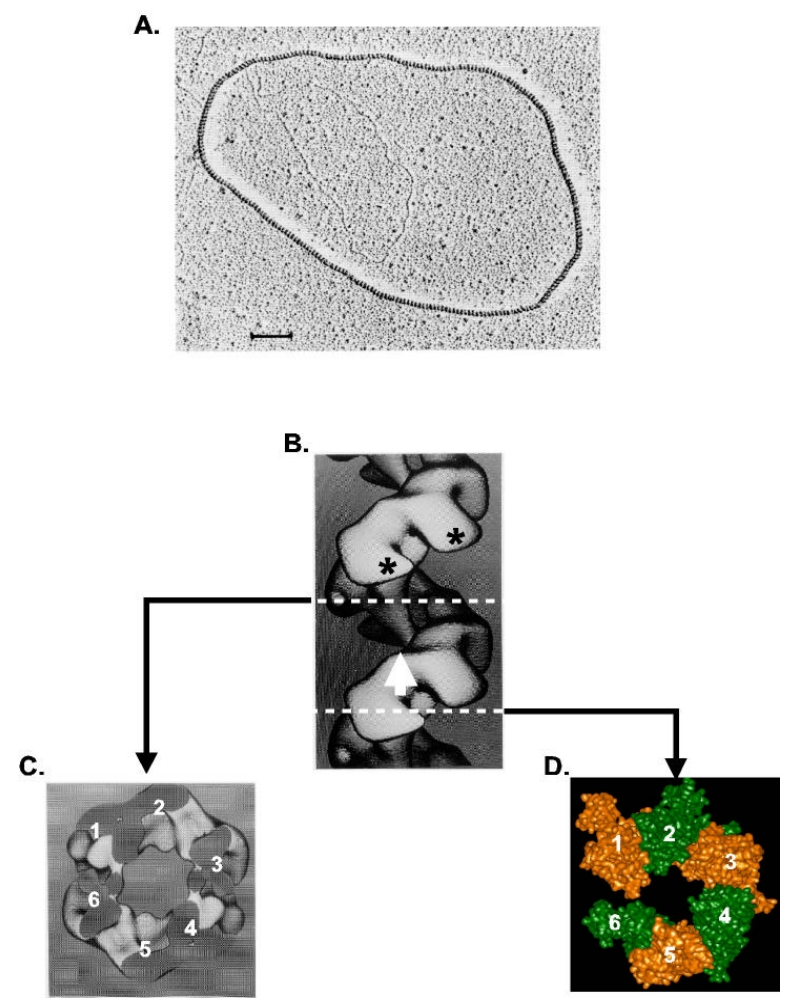

Figure : 3. The nucleoprotein filament formed by $\operatorname{Rec} A$ protein. (A), A filament formed on dsDNA with $\mathrm{ATP} \gamma \mathrm{S}$ as cofactor (Stasiak, A., and Egelman, E. H. (1988) in Genetic Recombination (Kucherlapati, R., and Smith, G. R., Eds.), American Society for Microbiology, Washington, D.

$$
\text { C., pp 265-308). }
$$

The striations in the filament are the groove which is discussed in the text. The bar in the figure represents $0.1 \mathrm{~nm}$. (B), A close-up of the filament (the DNA is not visible) shown in A. The asterisks indicates the lobes of monomers that protrude into the groove and the white arrow indicates the smooth surface of the groove. C and D are cross sections of the filament showing a single turn. The views shown in $\mathrm{B}$ and $\mathrm{C}$, are three dimensional re-constructions of electron micrographs of RecA filaments formed on dsDNA with $\mathrm{ATP} r \mathrm{~S}$. The view in $\mathrm{D}$, shows a single turn of the RecA filament as seen in the crystal structure. For this view, the individual monomers are coloured alternately in orange and yellow. The numbers in $\mathrm{C}$ and $\mathrm{D}$, indicate the 6 monomers making up the turn in the cross-section; the DNA would be located in the central hole in each cross-section.

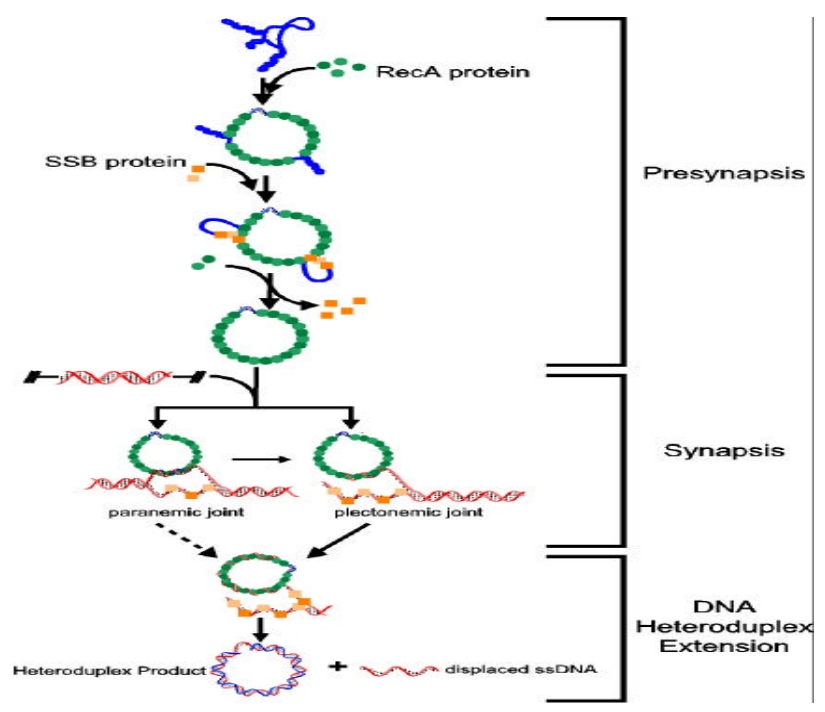

Figure: 4. The DNA strand exchange reaction promoted by the $\operatorname{RecA}$ protein. RecA protein is represented as a sphere and SSB protein as a square. The three stages shown are: presynapsis, synapsis and DNA heteroduplex extension.

Details are discussed in the text. This figure is adapted from Bianco, P. R., R

B. Tracy, and S. C. Kowalczykowski. (1998). DNA strand exchange proteins: A biochemical and physical comparison. Front Biosci 3:D570D603.

\section{Mechanism of RecA}

RecA's association with DNA major is based on its central role in homologous recombination. The RecA protein binds strongly and in long clusters to ssDNA to form a nucleoprotein filament. The protein has more than one DNA binding site, and thus can hold a single strand and double strand together. This feature makes it possible to catalyze a DNA synapsis reaction between a DNA double helix and a complementary region of single stranded DNA. The RecAssDNA filament searches for sequence similarity along the dsDNA. The search process induces stretching of the DNA duplex, which enhances sequence complimentarity recognition a mechanism termed conformational proofreading. The reaction initiates the exchange of strands between two recombining DNA double helices. After the synapsis event, in the heteroduplex region a process called branch migration begins. In branch migration an unpaired region of one of the single strands displaces a paired region of the other single strand, moving the branch point without changing the total number of base pairs. Spontaneous branch migration can occur, however as it generally proceeds equally in both directions it is unlikely to complete recombination efficiently. The RecA protein catalyzes unidirectional branch migration and by doing so makes it possible to complete recombination, producing a region of heteroduplex DNA that is thousands of base pairs long. ${ }^{6}$ 
Applications

- Visualization of DNA structures with electron microscopy.

- D-loop mutagenesis.

- Screening libraries using RecA-coated probes.

- Cleavage of DNA at any single predetermined site.

- RecA mediated affinity capture for full length cDNA cloning. $^{7-15}$

\section{SOS Response}

The SOS response was discovered and named by Miroslav Radman in 1975. The SOS response is a global response toDNA damage in which the cell cycle is arrested, DNA repair and mutagenesis are induced. The system involves the RecA protein ( $\operatorname{Rad} 51$ in eukaryotes). The RecA protein, stimulated by single-stranded DNA, is involved in the inactivation of the LexA repressor thereby inducing the response. It is an error-prone repair system. ${ }^{16,17}$

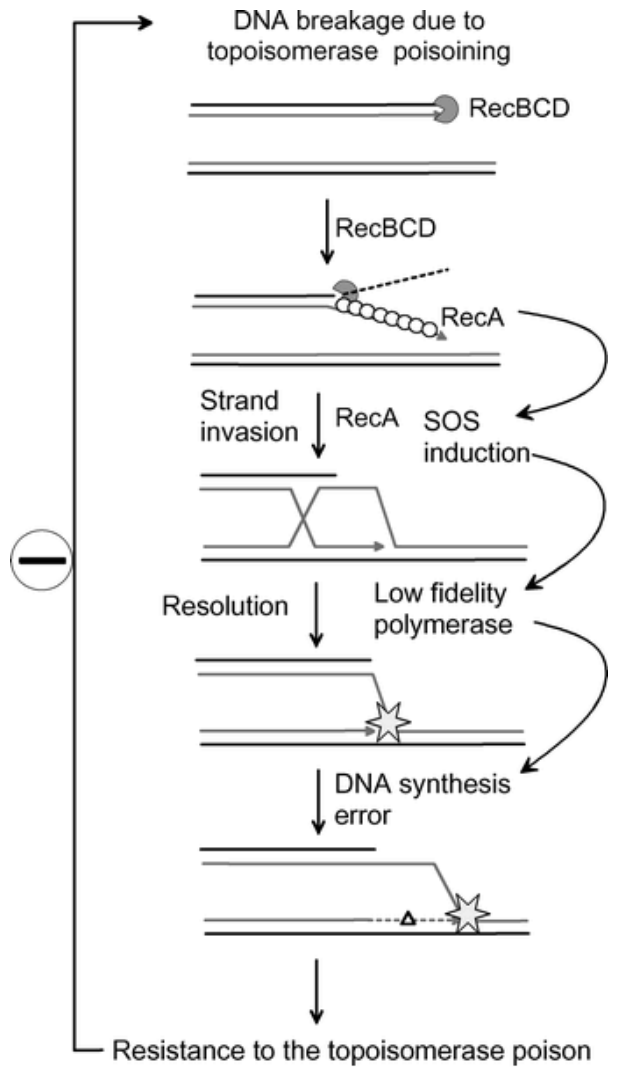

Figure 5: The SOS response has been proposed as amodel for bacterial evolution of certain types of antibiotic resistance.

\section{Mechnism of SOS}

During normal growth, the SOS genes are negatively regulated by LexA repressor protein dimers. Under normal conditions, LexA binds to a 20-bp consensus sequence (the SOS box) in the operator region for those genes. Some of these SOS genes are expressed at certain levels even in the repressed state, according to the affinity of LexA for their SOS box. Activation of the SOS genes occurs after DNA damage by the accumulation of single stranded (ssDNA) regions generated at replication forks, where DNA polymerase is blocked. RecA forms a filament around these ssDNA regions in an ATP-dependent fashion, and becomes activated. The activated form of RecA interacts with the
LexA repressor to facilitate the LexA repressor's selfcleavage from the operator.

Once the pool of LexA decreases, repression of the SOS genes goes down according to the level of LexA affinity for the SOS boxes. Operators that bind LexA weakly are the first to be fully expressed. In this way LexA can sequentially activate different mechanisms of repair. Genes having a weak SOS box (such as lexA, recA, uvrA, uvrB, and uvrD) are fully induced in response to even weak SOS-inducing treatments. Thus the first SOS repair mechanism to be induced is nucleotide excision repair (NER), whose aim is to fix DNA damage without commitment to a full-fledged SOS response. $^{18}$

\section{Antibiotic Resistance}

Recent research has shown that the SOS pathway may be essential in the acquisition of bacterial mutations which lead to resistance to some antibiotic drugs. The increased rate of mutation during the SOS response is caused by three lowfidelity DNA polymerases: Pol II, Pol IV and Pol V. Researchers are now targeting these proteins with the aim of creating drugs that prevent SOS repair. By doing so, the time needed for pathogenic bacteria to evolve antibiotic resistance could be extended, and thus improve the long term viability of some antibiotic drugs. ${ }^{19,20}$

\section{Repressor LexA}

LexA is a repressor enzyme (EC 3.4.21.88) that represses SOS response genes coding for DNA polymerases required for repairing DNA damage. LexA is intimately linked to RecA in the biochemical cycle of DNA damage and repair. RecA binds to DNA-bound LexA causing LexA to cleave itself in a process called autoproteolysis. ${ }^{21}$

\section{Infliction of DNA damage by the action of antibiotics}

- Bacteria require topoisomerases such as DNA gyrase or topoisomerase IV for DNA replication.

- Antibiotics such as ciprofloxacin are able to prevent the action of these molecules by attaching themselves to the gyrase - DNA complex.

- This is counteracted by the polymerase repair molecules from the SOS response. Unfortunately the action is partly counter productive because ciprofloxacin is also involved in the synthetic pathway of RecA type molecules which means that the bacteria responds to an antibiotic by starting to produce more repair proteins.

- These repair proteins can lead to eventual benevolent mutations which can render the bacteria resistant to ciprofloxacin.

- In the specific case of topoisomerases, some bacteria have mutated one of their amino acids so that the ciproflaxin can only create a weak bond to the topoisomerase. This is one of the methods that bacteria use to become resistant to antibiotics.

- Impaired LexA proteolysis has been shown to interfere with ciprofloxacin resistance. This offers potential for combination therapy that combine quinolones with strategies aimed at interfering with the action of LexA either directly, or via RecA.

- LexA contains a DNA binding domain, this is a variant form of the helix-turn-helix DNA binding motif. It is usually located at the $\mathrm{N}$-terminus of the protein. ${ }^{22}$ 


\section{CONCLUSION}

Identification of RecA in E.Coli raises the curtain for new era in the research and development sector of both existing and newer antibiotics in the field of pharmaceutical industry. Sothat it improves the therapeutic efficiency of the antibiotic by suppressing the resistance development of individual microbe.

\section{REFERENCES}

1. Anderson, D. G., and S. C.Kowalczykowski. Reconstitutionof an SOS response pathway: Derepression of transcription inresponse to DNA breaks. Cell in press. 1998. http://dx.doi.org/10.1016/S00928674(00)81721-3

2. Bianchi, M., C. DasGupta, and C. M.Radding. Synapsis and theformation ofparanemic joints by E. coli recA protein. Cell. 1983; 34:931-39. http://dx.doi.org/10.1016/0092-8674(83)90550-0

3. Cassuto, E., S. C. West, J. Mursalim, S. Conlon, and P. HowardFlanders. Initiation of genetic recombination: Homologous pairing between duplex DNA molecules promoted by recA protein. Proc. Natl. Acad. Sci. USA1980; 77:3962-66. http://dx.doi.org/10.1073/ pnas.77.7.3962 PMid:6449004 PMCid:349747

4. Cox, M. M., and I. R. Lehman. RecA protein of Escherichia coli promotes branch migration, a kinetically distinct phase of DNA strand exchange. Proc. Natl. Acad. Sci. USA1981;78:3433-37. http:// dx.doi.org/10.1073/pnas.78.6.3433 PMid:7022448 PMCid:319582

5. Dutreix, M., P. L. Moreau, A.Bailone, F. Galibert, J. R. Battista, G.C. Walker, and R. Devoret. New recA mutations that dissociate thevarious RecA protein activities in Escherichia coli provide evidence for an additional role for RecA protein in UV mutagenesis. J.Bacteriol 1989;171:2415-23. PMid:2651400 PMCid:209916

6. Egelman, E. H., and A. Stasiak. Structure of helical RecADNAcomplexes. Complexes formed in the presence of ATP-g-S or ATP. J. Mol. Biol. 1986; 191:677-97. http://dx.doi.org/10.1016/00222836(86)90453-5

7. Howard-Flanders, P., S. C. West, and A. Stasiak. Role of recA protein spiral filaments in genetic recombination. Nature (London) 1984; 309:215-20. http://dx.doi.org/10.1038/309215a0 PMid:6325943

8. Little, J. W., S. H. Edmiston, L. Z. Pacelli, and D. W. Mount. Cleavage of the Escherichia coli lexA protein by the recA protease. Proc. Natl.Acad. Sci. USA 1980; 77:3225-29. http://dx.doi.org/10.1073 /pnas.77.6.3225 PMid:6447873 PMCid:349587

9. Mazin, A. V., and S. C. Kowalczykowski. The function of the secondary DNA-binding site of RecA protein during DNA strand exchange. Embo J1998;17:1161-68.http://dx.doi.org/10.1093/emboj/17.4.1161 PMid:9463393 PMCid:1170464

10. McEntee, K., G. M. Weinstock, and I. R. Lehman. Initiation of general recombination catalysed in vitro by the recA protein of Escherichia coli. Proc.Natl. Acad. Sci. USA1979; 76:2615-19. http://dx.doi.org/10.1073/ pnas.76.6.2615 PMid:379861 PMCid:383658

11. Menetski, J. P., D. G. Bear, and S. C. Kowalczykowski. Stable DNA heteroduplex formation catalysed by the Escherichia coli RecA protein in the absence of ATP hydrolysis.Proc Natl Acad Sci. USA1990; 87:21-25. http://dx.doi.org/10.1073/pnas.87.1.21 PMid:2404275 PMCid:53191

12. Nohmi, T., J. R. Battista, L. A. Dodson, and G. C. Walker. RecAmediated cleavage activates UmuD for mutagenesis: mechanistic relationship between transcriptional derepression and posttranslational activation. Proc. Natl. Acad. Sci. USA1988; 85:1816-20. http://dx.doi.org/10.1073/pnas.85.6.1816 PMid:3279418 PMCid:279870

13. Ogawa, T., H. Wabiko, T. Tsurimoto, T. Horii, H. Masukata, and H.Ogawa. Characteristics of purified recA protein and the regulation of its synthesis in vivo. Cold Spring Harbor Symp. Quant. Biol. 1978; 43:909-16. http://dx.doi.org/10.1101/SQB.1979.043.01.099

14. Ogawa, T., X. Yu, A. Shinohara, and E. H. Egelman. Similarity of the yeast RAD51 filament to the bacterial RecA filament. Science1993; 259:1896-99. http://dx.doi.org/10.1126/science.8456314 PMid:8456314

15. Register, J. C., III, and J. Griffith. The direction of RecA protein assembly onto single strand DNA is the same as the direction of strand assimilation during strand exchange. J.Biol. Chem. 1985;260:12308-12. PMid:3900072

16. Roberts, J. W., C. W. Roberts, N. L.Craig, and E. M. Phizicky. Activity of the Escherichia coli recAgene product. Cold Spring Harbor Symp. Quant. Biol. 1978;43:917-20.http://dx.doi.org/10.1101/ SQB.1979.043.01.100

17. Shibata, T., C. DasGupta, R. P. Cunningham, and C. M. Radding. Purified Escherichia coli recA protein catalyzes homologous pairing of superhelical DNA and single-stranded fragments. Proc. Natl. Acad. Sci. USA $\quad 1979 ; 76: 1638-42$. http://dx.doi.org/10.1073/pnas.76.4.1638 PMid:156361 PMCid:383445

18. Story, R. M., I. T. Weber, and T. A.Steitz. The structure of the E. coli recA protein monomer and polymer. Nature (London) 1992;355:318-25. http://dx.doi.org/10.1038/355318a0 PMid:1731246

19. Tang, M., I. Bruck, R. Eritja, J.Turner, E. G. Frank, R. Woodgate,M. O'Donnell, and M. F. Goodman. Biochemical basis of SOSinduced mutagenesis in Escherichiacoli:reconstitution of in vitro lesion bypass dependent on the UmuD'2C mutagenic complex and RecA protein. Proc Natl Acad SciUSA1998;95:9755-60. http://dx.doi.org/10.1073/ pnas.95.17.9 755PMid:9707548 PMCid:21409

20. Bianco, P. R., R. B. Tracy, and S. C. Kowalczykowski. DNA strand exchange proteins: A biochemical and physical comparison. Front Biosci1998; 3:D570-D603. PMid:9632377

21. Camerini-Otero, R. D., and P. Hsieh. Homologous recombination proteins in prokaryotes and eukaryotes.Annu Rev Genet1995; 29:50952.http://dx.doi.org/10.1146/annurev.ge.29.120195.002453 PMid: 8825485

22. Eggleston, A. K., and S. C. West. Exchanging partners:recombination in E. coli. Trends Genet 1996;12:20-6. http://dx.doi.org/10.1016/01689525(96)81384-9

Cite this article as:

Ramani Gade, Mohini Swetha. RecA: A novel target for drug delivery. Int. Res. J. Pharm. 2013; 4(4):86-89 